\title{
Determinants of Scholar-Practitioner Gap in Kenyan Hospitality Industry
}

\author{
Muchai Peter Muthama ${ }^{1 *}$, Wadongo Billy Indeche ${ }^{2}$, Olielo Tom ${ }^{2}$ \\ ${ }^{1}$ Department of Hospitality and Tourism management, Kenya Methodist University-Kenya \\ ${ }^{2}$ Department of Eco-Tourism, Hotel and Institution Management, Maseno University-Kenya
}

*Corresponding Author: Muchai Peter Muthama, Department of Hospitality and Tourism management, Kenya Methodist University-Kenya

\begin{abstract}
Hospitality scholars and practitioners have varied interests and viewpoints that influence their respective priorities. These priorities include continuing education, professional recognition, and networking opportunities. The study objective was to identify the determinants of scholars-practitioners gap in the Kenyan hospitality industry. The study employed mixed method approach. Convergent research design was used. Population of the study included hospitality scholars in Kenyan universities and head of departments in 4- and 5-star hotels. The sample comprised of 224 practitioners, 162 scholars and 8 Key Industry Informants. Questionnaires, interviews and Focus Group Discussions were used to collect data. Qualitative data was summarized in categories and themes using thematic analysis. Factor analysis method was used to determine determinants of scholar-practitioners gap. Further analysis will included multiple regression and inferential statistics. Findings revealed that there existed a scholar-practitioner gap in Kenyan hospitality industry caused by lack of scholar-practitioner platform to interact, lack of organizational support, career differences and lack of time to interact. The study revealed that hospitality scholar-practitioner gap in Kenya has denied the parties an opportunity to interact and enhance their competencies.
\end{abstract}

Keywords: Determinants, scholar-practitioner gap, hospitality, Kenya

\section{INTRODUCTION}

Scholars and practitioners have frequently varied in interests and viewpoints that influence their respective priorities. These priorities include continuing education, professional recognition, organisational philosophy, networking opportunities as well as access to hospitality research publications. Differences exist in ways in which hospitality scholars and practitioners approach finding solutions to problems because of training and conditioning variations across the two occupations. This has been attributed by the view that, knowledge of theory and knowledge of practice as two distinct types of knowledge, which formulates different types of questions and require different solutions. Scholars and practitioners have varied research interests. Topics of interest to practitioners are rarely addressed in academic journals.

Hospitality practitioners have criticised hospitality degree curricula developed by scholars that do not offer a balance between teaching managerial skills and operational skills. Practitioners (employers) are concerned with how scholars are responding to the rapidly changing demands in the hospitality industry. Technology, the workforce, hospitality products and customers are constantly evolving. As a result of relevant competencies also evolve this leave scholar with outdated knowledge and skills that negatively affect their training competency. Lack of hospitality professional body in Kenya has denied scholars and practitioners an opportunity for interacting and improve their competencies. This study, therefore, investigated determinants of scholar-practitioner gap in Kenyan hospitality industry.

\section{LITERATURE REVIEW}

Beginning in the 1940s, scholars recognised a disparity between themselves and practitioners and thought of methods of bridging this gap. Evidence for this division includes recognition that academics and practitioners have different audiences, viewpoints, interests, intellectual approaches, research methods, and styles of discourse. Little has been studied about this topic, and few solutions for closing this gap have been offered, there is growing concern among hospitality scholars that this 
gap is increasing (Newland, 2000; Ospina \& Dodge, 2005a, 2005b). The unique approach of each respective group obstructs collaboration between themselves (Bolton et al. 2002). Different conditions motivate each group's search for knowledge. Scholars are usually interested in theoretical bias that advances their objective of original research and tenure (Bolton \& Stolcis, 2003). Practitioners, on the contrary, are in need of readily available knowledge for practical solutions to achieving organisational effectiveness (Bolton \& Stolcis, 2003). In Kenya the situation is no different, it is characterised by lack of forums such hospitality professional body where practitioners and scholars can engage in a meaningful manner.

\section{RESEARCH METHODOLOGY}

\subsection{Research Design}

The study used mixed method approach where researcher combined both quantitative and qualitative methods. The study used convergent design where both qualitative and quantitative data sets are collected and analysed simultaneously and data set merged into an overall interpretation (Creswell \& Plano, 2011). Quantitative and qualitative methods are usually given equal attention, so that each contributes equally to addressing the study research questions. The overall intent of triangulation design is to develop a better understanding of a topic by obtaining two different but complementary types of data (Morse, 2005).

\subsection{Population of the Study}

The population included both practitioners and scholars in Kenya. The sample included hospitality practitioners in 4 and 5-star hotels, hospitality scholars in universities offering hospitality and related degree programmes in Kenya and selected Key Industry Informants (KII). There were 27 universities offer degree programmes in hospitality and related courses in Kenya (CUE, 2019). According to Tourism Regulatory Authority (TRA,), there were twenty-eight (28) hotels which were classified as four and five star in Kenya (TRA, 2019).

\subsection{Sample Size}

Practitioners included hotel managers and head of operation departments and their assistants i.e. General/Hotel Managers, Accommodation/Housekeeping Managers, Food and Beverage Managers, Executive Chefs and Front Office Managers. Managers of the hotel support departments such as Finance, Human Resource, Maintenance, Security, ICT etc. did not participate in this study. Scholars included hospitality teaching faculty in Kenyan universities.

Key Industry Informants (KII) were also expected to participate. Using Kothari (2004) formula a minimum sample size required to achieve $95 \%$ confidence level (1.96), confidence interval $(0.05=$ \pm 5 ) and chances of picking a response of 50\% (0.5) the sample was 384. The study used questionnaires, interviews and FGD methods to collect data. Questionnaires will be developed to collect quantitative data while interviews and FGD were used to collect qualitative data. Three data collection methods were used to complement each other to increase credibility and validity of the findings. (Cohen et al, 2011). Questionnaires were self-administered with structured open and close ended questions. One FGD discussion was conducted with hospitality scholars and practitioners' respondents. Interviews were conducted to counter the weaknesses of FGDs by allowing the respondents to feel much more comfortable sharing the information confidentially only with the researcher (Kisilu \& Delno, 2010).

\subsection{Pre-Testing}

The purpose of pre-test is to determine the reliability of the research instruments. A convenience sample of four (4) hotels representing $10 \%$ of the total sample hotels and three (3) hospitality training institutions were selected for pre-testing. The pre-test sample was not part of the study sample. Collected pre-test data was checked for outliers and missing data. Analysis of the pre-test data was used to improve the validity and reliability of the research instruments. Revisions were made to the data collection instruments following the pre-testing analysis.

\subsection{Reliability and Validity of Research Instruments}

To establish the reliability of the instruments to the specific situation the coefficient of internal consistency the split-half reliability method will be used. The scores will then be divided into two comparable halves; the Spearman-Brown Proficiency Formula (r Split- Half) was used to correlate the 
two. The Slit-Half correlation for the questionnaire was 0.89. Questionnaires with a Split-Half estimate between 0.8 and 1.0 will be accepted as reliable enough (Gay, 1992). The interview guides for both one-on-one interviews and FGDs were subjected to critique from the university faculty members. A pre-test interview was also done to confirm that the interview and FGD tools capture the details clearly and accurately. The pre-test helps in enhancing the validity and reliability of the instruments and improve the questionnaire consistency and clarity. During the personal interviews, efforts were made to ensure careful note taking in order to reduce the risk of wrongly-interpreted answers during transcription of interviews, and to be able to double-check the answers after the interview.

\subsection{Data Analysis}

Data was entered into the Microsoft Excel spreadsheet and then exported to the Statistical Package for Social Science (SPSS) version 21.0 for analysis. Appropriate statistical techniques will then be applied for analysing data (Nachmias \& Nachmias, 2008). Both descriptive and inferential analyses were undertaken. Initial stages of quantitative analysis included analysis of means, standard deviations, medians, frequencies, and percentages. Means was used to rank the determinants of scholarpractitioners gap. A Principal Component Analysis with varimax rotation was also performed on seven (7) determinants of scholars-practitioners gap to examine the dimensionality and to find out which factors which had the highest influence.

\section{RESULTS AND DISCUSSION}

\subsection{Demographic Statistics}

A total of 389 respondents participated in this study. Hospitality practitioners were 226 and scholars were 163 which translated to $58 \%$ and $42 \%$ respectively. Among the hospitality practitioners' male were the majority with $\mathrm{n}=122(61.9 \%)$ and female $\mathrm{n}=75(38.1 \%)$ while females were a majority among the hospitality scholars at $n=87(53.4 \%)$ and with $n=76(46.6 \%)$. In Marital status, Married practitioners were $n=145(74.4 \%)$ and single were $n=50(25.6 \%)$ while married scholars were $n=118$ (74.2\%), $\mathrm{n}=38(23.9 \%)$ were single with others having $\mathrm{n}=3$ (1.9\%). Married respondents were the majority of both practitioners and scholars. In education among the hospitality practitioners, the degree holders were the majority of the respondents at $n=87(44 \%)$, however, among scholars the majority of the respondents were Master holders at $n=81$ (49.4\%).

\subsection{Determinants of Scholars-Practitioners Gap in the Kenyan Hospitality Industry}

Both hospitality scholars $(n=142,86.6 \%)$ and practitioners $(n=167,79.9 \%)$ believed that of the hoteliers and trainers believe there is a gap between hospitality educators and workers. The objective was to identify the determinants of scholar-practitioners gap in Kenya hospitality industry. In a scale of between 1- 5 respondents were asked to rate the extent to which identified determinants contributed to the scholar-practitioner gap. Factor analysis using mean was conducted for both scholars and practitioners together and the separately (See Table 1 below).

Table1: Descriptive Statistics for determinants of scholar-practitioners gap

\begin{tabular}{|c|c|c|c|c|c|c|}
\hline & & $\begin{array}{l}\text { Both } \\
\text { \& Pra }\end{array}$ & titioners & Scholars & Practitioners & Chi-Square Tests \\
\hline $\begin{array}{l}\text { Determinants of scholars-practitioners } \\
\text { gap }\end{array}$ & Rank & Mean & $\mathrm{SD}$ & Mean & Mean & \\
\hline $\begin{array}{l}\text { Lack of platforms for scholar and } \\
\text { practitioners to interact }\end{array}$ & 1 & 4.07 & 0.994 & 4.2 & 4.10 & $\begin{array}{l}\chi^{2}=6.998 \\
\mathrm{df}=4, \text { Sig. }=0.136\end{array}$ \\
\hline Lack of organizational support & 2 & 3.88 & 1.043 & 3.86 & 3.91 & $\begin{array}{l}\chi^{2}=36.519 \\
\mathrm{df}=4, \text { Sig. }<0.001\end{array}$ \\
\hline $\begin{array}{l}\text { Lack of time for scholars and } \\
\text { practitioners to interact }\end{array}$ & & 3.88 & 1.067 & 3.92 & 3.85 & $\begin{array}{l}\chi^{2}=2.037 \\
\mathrm{df}=4, \text { Sig. }=0.729\end{array}$ \\
\hline $\begin{array}{l}\text { Lack of strong hospitality professional } \\
\text { association in Kenya }\end{array}$ & & 3.81 & 1.239 & 3.79 & 3.83 & $\begin{array}{l}\chi^{2}=33.550 \\
\mathrm{df}=4, \text { Sig. }<0.0001\end{array}$ \\
\hline $\begin{array}{l}\text { "Know it all" altitude of the scholars } \\
\text { towards practitioners }\end{array}$ & & 3.65 & 1.311 & 3.55 & 3.72 & $\begin{array}{l}\chi^{2}=3.557 \\
\mathrm{df}=4, \text { Sig. }=0.469\end{array}$ \\
\hline $\begin{array}{l}\text { Career differences between scholars } \\
\text { and practitioners }\end{array}$ & & 3.62 & 1.009 & 3.72 & 3.55 & $\begin{array}{l}\chi^{2}=27.265 \\
\mathrm{df}=4, \text { Sig. }<0.0001\end{array}$ \\
\hline $\begin{array}{l}\text { Lack of benefits associated with } \\
\text { scholar-practitioner interaction }\end{array}$ & & 3.54 & 1.246 & 3.65 & 3.46 & $\begin{array}{l}\chi^{2}=12.825 \\
\mathrm{df}=4, \text { Sig. }=0.012\end{array}$ \\
\hline
\end{tabular}


Note: 5=Very Great Extent, 4=Great Extent, 3= Moderate Extent, 2= Small Extent, 1= Not at all $\mathrm{n}=377$

Independent variable: I believe there is a gap between hospitality scholars and practitioners had significant a chi-square dependency at $95 \%$ confidence interval of 0.05

The findings showed that "Lack of platforms of scholars and practitioners to interact" was first determinant of scholar-practitioner gap by both the scholars and practitioners with a mean of 4.07 (great extent) effect and had a chi-square association at $\chi^{2}=6.998, \mathrm{df}=4, \mathrm{Sig} .=0.136$. "Lack of organizational support" was ranked second determinant of scholar-practitioner gap by practitioners and third by scholars with a mean of 3.91 (great extent) and 3.81 (great extent) respectively. While scholars ranked "lack of time to interact" as second determinant of scholar-practitioner gap with a mean of 3.92 (great extent), practitioners ranked it third with a mean of 3.86 (great extent). "Lack of strong hospitality professional association in Kenya" was ranked fourth determinant by both scholars and practitioners with a mean of 3.81 (great extent) and had a chi-square association at $\chi^{2}=33.550$, $\mathrm{df}=4$, Sig. $<0.0001$. The findings showed that "Know it all" altitude of the scholars towards practitioners" was ranked $7^{\text {th }}$ (last) by scholars and $5^{\text {th }}$ by the practitioners with the mean of 3.55 (great extent) and 3.72 (great extent) respectively. "Career differences between scholars and practitioners" had a mean of 3.62 (great extent) while "lack of benefits associated with scholar-practitioner interaction" had a least mean of 3.54 (great extent) and had a chi-square association at $\chi^{2}=12.825$, $\mathrm{df}=4$, Sig. $=0.012$ (See table 4.2). This means that if hospitality scholars and practitioners in Kenya are given vibrant platforms to interact, given support by their employers and there is presence of active professional association in Kenya then these would significantly eradicate scholar-practitioner gap in Kenya. Hoteliers and scholars should therefore endeavour to include each other in their activities with the support of the employer to bridge on scholar-practitioner gap.

\subsection{Factor Analysis}

A Principal Component Analysis with varimax rotation was performed on seven (7) determinants of scholars-practitioners gap in the Kenyan hospitality industry measures in order to examine the dimensionality of determinants of scholars-practitioners gap in the Kenyan hospitality industry and also to find out if all the variables were significant. The other objective was to group the common factors and to retain a small number of factors which had the highest influence.

KMO test measures sample adequacy and ranges between 0 and 1 . A value close to 1 indicates that patterns of correlations are compact and hence the Factor Analysis is reliable and appropriate for the study. KMO measures on determinants of scholars-practitioners gap in the Kenyan hospitality industry was 0.767 which represented great acceptability of the use of factor analysis and sufficient for intercorrelations.

Bartlett's test checks if the observed correlation matrix diverges significantly from the identity matrix. Bartlett's test of Sphericity was significant (chi-square $=459.839, \mathrm{p}<0.0001$ ). Total variance explained for the determinants of scholars-practitioners gap in the Kenyan hospitality industry constructs was explained (See Table 2 below). The analysis of variance identified the Eingen values which is the variance of each factor or component in comparison with the total variance of all the items in the construct. Other elements in the analysis of variance include the percentage of variance and also the cumulative percentages which were explained by the extracted factors before and after the rotation.

Table2: Total variance explained for the determinants of scholars-practitioners gap

\begin{tabular}{|c|c|c|c|c|c|c|c|c|c|}
\hline \multirow[t]{2}{*}{ Component } & \multicolumn{3}{|c|}{ Initial Eigenvalues } & \multicolumn{3}{|c|}{$\begin{array}{l}\text { Extraction Sums of Squared } \\
\text { Loadings }\end{array}$} & \multicolumn{3}{|c|}{$\begin{array}{c}\text { Rotation Sums of Squared } \\
\text { Loadings }\end{array}$} \\
\hline & Total & $\begin{array}{l}\% \\
\text { Variance }\end{array}$ & $\begin{array}{l}\text { Cumulative } \\
\%\end{array}$ & Total & $\begin{array}{l}\% \\
\text { Variance }\end{array}$ & $\begin{array}{l}\text { Cumulative } \\
\%\end{array}$ & Total & $\begin{array}{l}\% \\
\text { Variance }\end{array}$ & $\begin{array}{l}\text { Cumulative } \\
\%\end{array}$ \\
\hline 1 & 2.758 & 39.402 & 39.402 & 2.758 & 39.402 & 39.402 & 2.179 & 31.133 & 31.133 \\
\hline 2 & 1.048 & 14.966 & 54.369 & 1.048 & 14.966 & 54.369 & 1.627 & 23.236 & 54.369 \\
\hline 3 & .923 & 13.185 & 67.554 & & & & & & \\
\hline 4 & .715 & 10.212 & 77.765 & & & & & & \\
\hline 5 & .607 & 8.671 & 86.436 & & & & & & \\
\hline 6 & .491 & 7.007 & 93.444 & & & & & & \\
\hline 7 & .459 & 6.556 & 100.000 & & & & & & \\
\hline
\end{tabular}


Principal Component Analysis with a Varimax rotation was used to analyze the seven factors related to determinants of scholars-practitioners gap in the Kenyan hospitality industry. The correlation matrices among the items revealed a number of correlations in excess of 2 which meant that all responses were suitable for factorization. From the Variance matrix, there were two variables that had Eingen values of more than 1.0 which meant that these were the variables that had the highest influence on scholars-practitioners gap in the Kenyan hospitality industry.

Component one had the highest variance of 2.758 which accounted for $39.402 \%$ of the variance. Component 2 had the second highest variance of 1.048 contributing $14.966 \%$ of the variance. The cumulative results showed that there were two critical factors determining scholars-practitioners gap in the Kenyan hospitality industry which accumulated to $54.369 \%$ of the total variance in the construct. The other five factors explained the variance at less than $46 \%$ which meant that some variance had been explained by latent variables.

In evaluating what variables to retain, factor loadings were taken into account and the minimum factor loadings was 0.607 which is considered to be moderately high. The factors affecting one variable were all loaded up together and given a name so that the factors were reduced to a minimum of three. The researcher, however chose to delete all the other which did not relate to either factor 1 or 2 in order to do further relationships (See Table 3 below).

Table3: Rotated Component Matrix ${ }^{a}$

\begin{tabular}{|l|l|l|}
\hline \multicolumn{1}{|c|}{ Determinants of Scholar-Practitioner gap } & \multicolumn{2}{c|}{ Component } \\
\cline { 2 - 3 } & 1 & 2 \\
\hline Lack of platforms for Hospitality Scholars and Practitioners to interact & .579 & .232 \\
\hline Career differences between Hospitality Scholars and Practitioners & -.004 & .814 \\
\hline Lack of time for Hospitality Scholars and Practitioners to interact & .269 & .751 \\
\hline Lack of organizational support & .788 & -.001 \\
\hline Lack of benefits associated with Hospitality Scholars and Practitioners interaction & .509 & .522 \\
\hline "Know it all" altitude of the Hospitality scholars towards Hospitality practitioners & .787 & .102 \\
\hline Lack of strong Hospitality professional association in Kenya & .522 & .252 \\
\hline Extraction Method: Principal Component Analysis & \\
Rotation Method: Varimax with Kaiser Normalization & \\
\hline a. Rotation converged in 3 iterations & \\
\hline
\end{tabular}

From the rotation matrix two factors were obtained explaining $54.369 \%$ of the total variance of determinants of scholars-practitioners gap in the Kenyan hospitality industry. These two factors were grouped as component 1 and component 2. Component 1 had two determinants namely; "lack of organizational support" and "Know it all altitude of the Hospitality scholars towards practitioners". Component 2 had two determinants namely; "career differences" and "lack of time for scholars and practitioners to interact". The results meant that all the determinants of scholars-practitioners gap in the Kenyan hospitality industry were correlated to the two components.

Using the two components, a scale was created using the average means of each construct. A scale of 1-5 was created and all the means of all the items in each component were analyzed. Component 1 had an average mean of 3.77 while component 2 had a mean of 3.75. Five constructs namely; Lack of platforms for Hospitality scholars and practitioners to interact, Lack of benefits associated with scholar-practitioner interaction and Lack of strong hospitality professional association in Kenya were then excluded from further analysis because they were deemed to have low means and as such much of their influence could be explained by the other analysis methods.

Regression model on gap between hospitality educators and workers had a coefficient of determination R square is 0.732 and Adjusted $\mathrm{R}$ Square is 0.729 . The coefficient of determination $\mathrm{R}$ square indicates that $73.2 \%$ of the variation on the gap between hospitality scholars and practitioners is explained by the variation in contributors of the two components. This indicates a good model fit.

\subsection{Regression Coefficients of Determinants of Scholar-Practitioner Gap}

The study further determined the beta coefficients of gap between hospitality scholars and practitioners versus contributors of hospitality scholars and practitioners' gap (See table 4 below). The table shows that the coefficient of career differences, Lack of time for scholars and practitioners to interact, Lack of organizational support and "Know it all" altitude of scholars towards practitioners 
had $p$-value of $<0.0001$ which was less than 0.05 . This $p$ value confirms that these determinants of scholar-practitioner gap were significant at $95 \%$ confidence.

Table4: Determinants of scholar-practitioner gap Regression coefficients ${ }^{a}$

\begin{tabular}{|c|c|c|c|c|c|c|}
\hline \multirow{2}{*}{\multicolumn{2}{|c|}{ Model }} & \multicolumn{2}{|c|}{$\begin{array}{l}\text { Unstandardized } \\
\text { Coefficients }\end{array}$} & \multirow{2}{*}{$\begin{array}{l}\text { Standardized } \\
\text { Coefficients } \\
\text { Beta }\end{array}$} & \multirow[t]{2}{*}{$\mathbf{t}$} & \multirow[t]{2}{*}{ Sig. } \\
\hline & & $\mathrm{B}$ & Std. Error & & & \\
\hline 1 & (Constant) & .599 & .105 & & 5.709 & .000 \\
\hline & Career differences & .196 & .022 & .265 & 8.833 & .000 \\
\hline & Lack of time to interact & .199 & .022 & .284 & 9.237 & .000 \\
\hline & Lack of organizational support & .227 & .022 & .317 & 10.473 & .000 \\
\hline & $\begin{array}{l}\text { "Know it all" altitude of scholars towards } \\
\text { practitioners }\end{array}$ & .222 & .017 & .390 & 13.051 & .000 \\
\hline
\end{tabular}

\section{CONCLUSION}

Lack of scholar-practitioner platform to interact and lack of stable hospitality professional association in Kenya were the main contributor of scholar-practitioner gap in Kenya. This gap has affected the work competence of both scholars and practitioners. Scholars' knowledge is lags behind the industry trends which is transmitted to their students. Practitioners on the other side fail to get new knowledge generated by scholars particularly in research that cam enhance their work performance. To bridge hospitality scholar-practitioner the gap in Kenya, scholars and practitioners need to be enlightened on the benefits of bridging scholar-practitioner gap. This can be fuelled through organizational support including facilitation and providing time for such activities.

\section{REFERENCES}

[1] Kenya National Bureau of Statistics (2016). Economic Survey 2016.Republic of Kenya. Nairobi, Kenya.

[2] Newland, C., (2000). The Public Administration Review and ongoing struggles for connectedness. Public Administration Review, 22:49-57.

[3] Ospina, S., \& Dodge, J. (2005). It's about time: Catching method up to meaning-the usefulness of narrative inquiry in public administration research. Public Administration Review, 56: 284:290.

[4] Ospina, S., \& Dodge, J. $\left(2005^{\mathrm{b}}\right)$. Narrative inquiry and the search for connectedness: Practitioners and academicians developing public administration scholarship. Public Administration Review, 127 (3): 376-407.

[5] Bolton, M., \& Stolcis, G., (2003). Ties that do not bind: Missing on the specious relevance of academician research. Public Administration Review, 22:87-94.

[6] Creswell, J. (2008). Research design: Qualitative, quantitative, and mixed methods approaches ( ${ }^{\text {rd }}$ Ed.). Thousand Oaks, CA: Sage Publications

[7] Creswell, J. \& Plano C. (2007). Designing and conducting mixed methods research. Thousand Oaks, CA: Sage.

[8] Plano C. \& Creswell, J. (2008). the mixed methods reader. Thousand Oaks, CA: Sage.

[9] Morse, J. M. (2005). Evolving trends in qualitative research: Advances in mixed methods designs. Qualitative Health Research, 15:7:14.

[10] Cohen, L., Manion, L. \& Morrison, K. (2011). Research Methods in Education. (7 ${ }^{\text {th }}$ Ed.). New York: Routledge. (705 sider). Støttelitteratur: Kleven, T. A. (Red.).

[11] Gay, L., (1992). Research Methods for Business and Management. Macmillan, Coll. Div.

[12] Kisilu K. \& Delno L. (2006). Proposal and Thesis Writing: An Introduction. Paulines Publications Africa. ISBN $9966-08-133 X$.

Citation: Muchai Peter Muthama, et.al. "Determinants of Scholar-Practitioner Gap in Kenyan Hospitality Industry". International Journal of Research in Tourism and Hospitality (IJRTH), vol 5, no. 4, 2019, pp. 0106. doi: http://dx.doi.org/10.20431/2455-0043.0504001.

Copyright: () 2019 Authors. This is an open-access article distributed under the terms of the Creative Commons Attribution License, which permits unrestricted use, distribution, and reproduction in any medium, provided the original author and source are credited. 